Muhammad M, Armstrong M, Elgendy MA. Non-isolated, high gain, boost converter for power electronic applications. In: 8th IET International Conference on Power Electronics, Machines and Drives (PEMD 2016). 19-21 April 2016, Glasgow, UK: Institution of Engineering and Technology.

DOI link

http://dx.doi.org/10.1049/cp.2016.0211

ePrints link

http://eprint.ncl.ac.uk/227923

Date deposited

$02 / 05 / 2018$

Copyright

This paper is a postprint of a paper submitted to and accepted for publication and is subject to Institution of Engineering and Technology Copyright. The copy of record is available at the IET Digital Library. 


\title{
Non-isolated, High Gain, Boost Converter for Power Electronic Applications
}

\author{
M. Muhammad, M. Armstrong, M. A. Elgendy \\ School of Electrical \& Electronic Engineering Newcastle University, United Kingdom \\ m.muhammad@ncl.ac.uk,matthew.armstrong@ncl.ac.uk,
}

Keywords: Non-isolated, high step-up, coupled inductor, switched capacitor, passive clamp circuit.

\begin{abstract}
This paper presents a new non-isolated high gain, boost converter for power electronic applications, such as renewable energy and electric vehicle systems. The converter uses a coupled inductor and switched capacitor to achieve the high step up voltage requirements. Importantly, the structure of the high voltage side, together with the switched capacitor, reduces the voltage stress across the diodes; thus enhancing the capability of the circuit. Furthermore, the semiconductor switch voltage stress is reduced to less than one third of the output voltage. The main switch achieves zero current switching (ZCS) turn-on performance and all diodes achieve (ZCS) turn off reducing reverse recovery losses. As a result, the circuit exhibits high efficiency performance; which is essential in most modern power electronic applications. In this paper, the operational principle and performance of the proposed converter is presented and validated experimentally with a $250 \mathrm{~W}, 20 \mathrm{~V}$ input voltage / $190 \mathrm{~V}$ output voltage prototype circuit.
\end{abstract}

\section{Introduction}

There is an increasing demand in power electronic systems, such as renewable energy, energy storage, and electric vehicle applications, for high gain dc-dc converters. Classic isolated power converter topologies, such as the flyback or push-pull converter, can readily achieve the necessary high gain by adjusting the transformer turns ratio [1] [2]. However, to overcome the problem of large voltage spikes observed by the primary switch at turn-off (due to leakage inductance), traditionally required a snubber. Likewise, non-isolated topologies such as switched capacitors, voltage multiplier cells, and voltage lift circuits, all require more elaborate control strategies and multiple cells to achieve high voltage conversion ratios. This typically results in complex structures. A common alternative technique is to use a coupled inductor to enlarge the voltage gain in non-isolated dc-dc converters [3-5]. Coupled inductor boost converters can provide high voltage gain without extreme duty cycle operation, with a relatively simple topology. Consequently, they can reduce the switch voltage stress and allow the use of low voltage rated, high performance, semiconductor devices. However, the main drawbacks of coupled inductor converters typically include severe voltage spikes across the switch due to the leakage energy of the coupled inductor and the large input current ripple. Beside capacitor charge transference [6], [7] and magnetic coupling converters [8], [9] one can find other promising hybrid topologies for high step-up dc-dc conversion [10-12]. This technique has been successfully applied in many converters and achieves good overall performance. To limit the switch voltage stress due to the leakage energy of the coupled inductor, active clamp energy recycling schemes have also been proposed. However, this increases cost, which may be problematic in cost sensitive applications. Also, any overlap can lead to failure of the circuit, thereby reducing the reliability of the circuit. Methods of estimating the parameters of dc-dc converters, system identification and control can as well be found in [13-16].

This paper proposes a new boost dc-dc converter topology with the objective to achieve high voltage gain operation with a robust well-regulated dc output voltage; whilst minimizing the semiconductor device stress typically observed in power converters of a similar type. To achieve this goal a high step up dc-dc converter with coupled inductor and switched capacitor is adopted. Here, the two capacitors are charged in parallel by the coupled inductor and discharged in series to enlarge the voltage gain. A passive clamp circuit is employed to recycle the leakage inductance energy whilst minimizing the turn-off voltage spike across the main switch. Importantly, the clamp circuit provides a mechanism of achieving zero current switching (ZCS) for the main switch and subsequent reduction of the output diodes current fall rate. Consequently, the diodes switching loss and output switching noise are decreased. In addition, low rated semiconductor devices can be used, which in turn helps to reduce conduction losses. To achieve ZCS over a wide operating range in the proposed circuit, the inherent leakage inductance of the coupled inductor is used. In the following, the operating principles of the proposed dc-dc converter are described in full detail. Experimental results from a $250 \mathrm{~W}$ prototype circuit are then presented to validate the advantageous performance and operation of the high voltage gain circuit

\section{Converter Operational Analysis}

\subsection{Circuit Description}

The converter employs one coupled inductor denoted as $L$. The primary and secondary windings of the coupled inductor are denoted as $L_{a}$ and $L_{b}$ respectively. The primary winding 


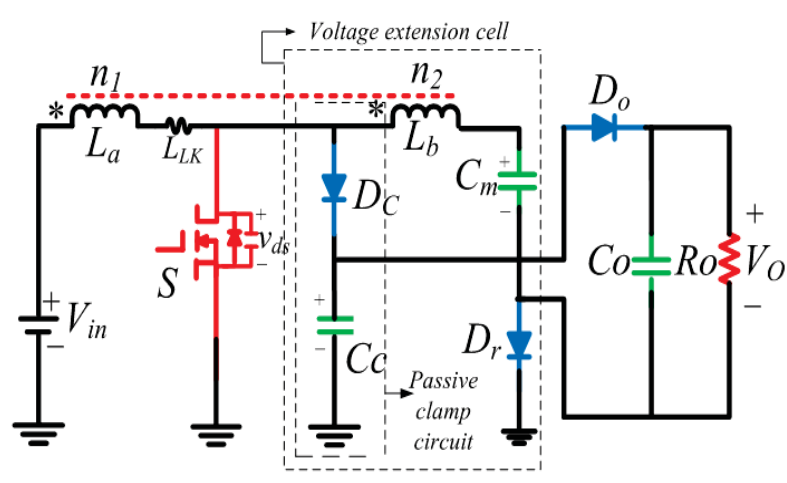

Fig. 1: Circuit configuration of the proposed converter

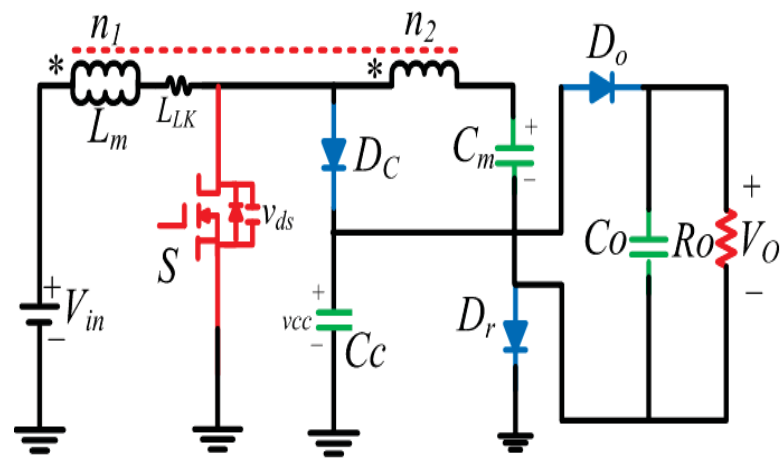

Fig. 2: Equivalent circuit

$L_{a}$ serves as a filter inductor, similar to a conventional boost converter, and is coupled to its corresponding secondary winding $L_{b}$. The primary and secondary windings of the coupled inductor is represented by $n_{1}$ and $n_{2}$, and the coupling reference denoted by ' $*$ ', The converter main switch is denoted by $S$. The passive clamp circuit consists of clamping diode $D_{c}$ and the clamp capacitor $C_{c}$. The voltage extension cell consists of the secondary winding of the couple inductors $L_{b}$, the clamp diode $D_{c}$, clamp capacitor $C_{C}$, regenerative diode $D_{r}$ and the switched capacitor $C_{m} . D_{o}, C_{o}$ are the output diode and filter capacitor; $R_{O}$ denotes the output resistive load.

Fig. 2 shows the equivalent circuit of the proposed high stepup boost converter. The coupled inductor can be modelled as an ideal transformer with defined turns ratio. The ideal transformer primary winding is in parallel with magnetizing inductor $L_{m}$ and then in series with a leakage inductance $L_{L k}$ [4], [5]. $V_{\text {in }}, V_{o}$ are the input and output voltages of the converter respectively.

To simplify the converter analysis the following assumptions are made:

1) The power switch is ideal, but the parasitic capacitor is considered in the analysis.

2) Capacitors $C_{c}, C_{m}$ and $C_{o}$ are large enough. Thus, their voltages are constant in one switching cycle.

3) The turns ratio of the coupled inductor $N$ is equal to $n_{2} / n_{1}$ and coupling coefficient $k$ is expressed as $L_{m} / L_{L k}+L_{m}$

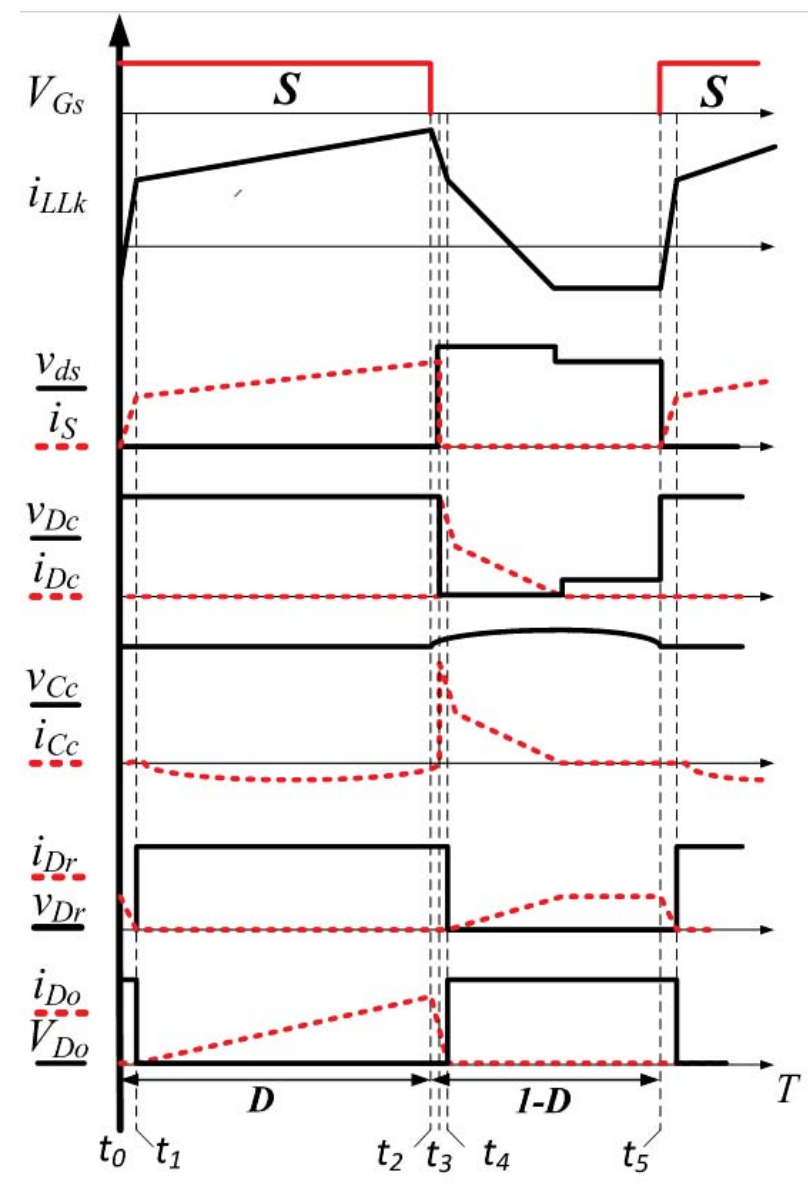

Fig. 3: key waveforms of proposed converter

\subsection{Operational Modes}

The following discussion is confined to continuous current mode (CCM) operation, since the converter design is based on CCM and the operation is guaranteed throughout the full range of the duty cycle variation with resistive loads. During steady state operation, the duty cycle $D$ is higher than 0.5 . The clamp diode $D_{c}$ turns on and turns off naturally. Some typical steady state waveform of the proposed converter in CCM operation is shown in Fig. 3 There are five modes of operation in one switching cycle; the equivalent circuits and current flow path corresponding to each operational stage are shown in Fig. 4. The converter operation in CCM is analysed as follows:

Mode $1\left[t_{0}-t_{1}\right]$ (Fig. a): Before time $t_{1}$, the main switch $S$ is conducting. The clamp diode $D_{C}$ and output diode $D_{o}$ are reversed biased whilst the regenerative diode $D_{r}$ is also conducting. The current through regenerative diode decreases linearly. The rate of decrease in current is controlled by the leakage inductance $L_{L K}$. Magnetizing inductance $L_{m}$ is charged by the input voltage $V_{\text {in }}$, whilst the switched capacitor is charged through the coupled inductor secondary winding. The load is supplied by the output capacitor.

Mode $2\left[t_{1}-t_{2}\right]$ (Fig. b): The regenerative diode $D_{r}$ turns off softly at time $t_{1}$ under ZCS. The output diode $D_{0}$ becomes forward biased. During this time the clamp 

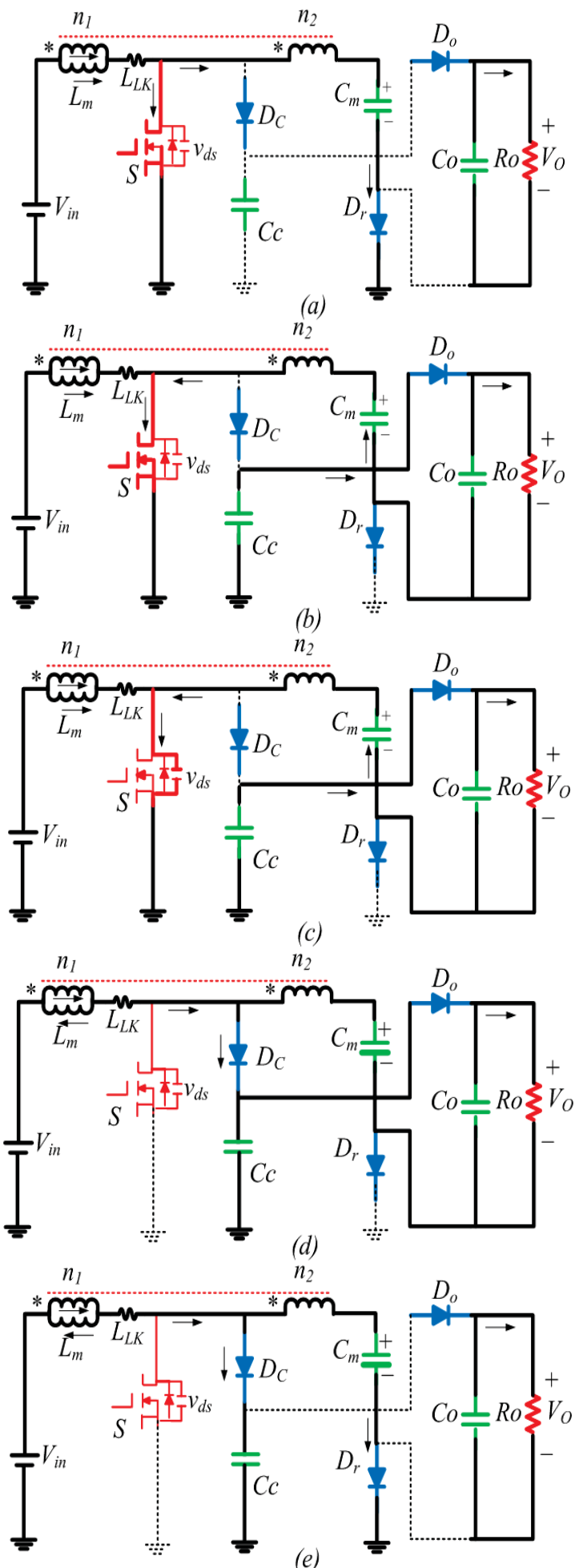

Fig. 4: Operational modes equivalent circuit

(a) Mode $1\left[t_{0}-t_{1}\right]$, (b) Mode $2\left[t_{1}-t_{2}\right]$, (c) Mode $3\left[t_{2}-t_{3}\right]$,

(d) Mode $4\left[t_{3}-t_{4}\right]$, (e) Mode $5\left[t_{4}-t_{5}\right]$

capacitor $C_{c}$, the switched capacitor $C_{m}$ and the coupled inductor secondary winding are in series to enlarge the voltage gain. Meanwhile, the converter operates in flyback mode to supply the load.

Mode $3\left[t_{2}-t_{3}\right]$ (Fig. c): At time $t_{2}$ the main switch $S$ turns off, diode $D_{c}$ and $D_{r}$ are reversed biased whilst $D_{o}$ is forward biased. The magnetizing inductor current charges the parasitic capacitor of the switch. This mode is very short and ended when $V_{c c}=V_{i n}+V_{d s}$.

Mode $4\left[t_{3}-t_{4}\right]($ Fig d): The voltage across the switch $S$ rises to the clamp capacitor voltage and the clamp diode $D_{C}$ become forward biased. The leakage inductor current $i_{L L k}$ is commutated to the clamp diode and the leakage inductance energy is released to the clamp capacitor $C_{c}$. The voltage across the switch $S$ is clamped to the clamp capacitor voltage $v_{c c}$. During this time, the leakage inductance current and that of output diode $D_{o}$ decreases linearly. The current decrease rate of the output diode is controlled by the inherent leakage inductance of the coupled inductor.

Mode $5\left[t_{4}-t_{5}\right]$ (Fig. e): The output diode turns off softly under ZCS at the end of mode 4 . The regenerative diode $D_{r}$ begins to conduct, the diode current rises linearly and that of the leakage inductance decreases linearly. The clamp and switched capacitor are now charged in parallel by the input voltage source $V_{\text {in }}$. The load is supplied by the output capacitor during this time. At the end of this mode the clamp diode $D_{C}$ turns off naturally at time $t_{5}$, and the main switch $S$ turns on with ZCS performance.

\section{Circuit Analysis}

\subsection{Voltage Conversion Ratio}

The parasitic parameters inherent in the power devices are not included in the analysis; this includes the leakage inductance of the coupled inductor. The magnetising inductor current is also considered to be linear. The switching period consists of the on and off period. When the power switch is in the on state, the magnetizing inductor is charged linearly by the input voltage. Using KVL, the voltage across the magnetizing inductor is given by

$$
V_{L m}=V_{\text {in }}
$$

The corresponding voltage across the secondary winding of the coupled inductor is

$$
V_{L b}=N V_{L m}
$$

At the same time instant, diode $D_{r}$ is reversed blocking and the output diode $D_{o}$ is forward conducting, the clamp capacitor and switched capacitor discharge in series and the power is transferred to the load; the output voltage can be described by

$$
V_{0}=V_{C m}+V_{C C}+N V_{\text {in }}
$$

By applying the inductor volt-second balance principle to the clamp capacitor, the voltage across the clamp capacitor can be expressed as

$$
V_{c c}=\frac{V_{i n}}{(1-D)}
$$

When the main switch $S$ turns off, the clamp and regenerative diode turns on, the clamp and switched capacitors are charged in parallel by the input voltage, the voltage across the switched capacitor is derived as

$$
V_{C m}=N\left(V_{C C}-V_{i n}\right)+V_{C C}
$$




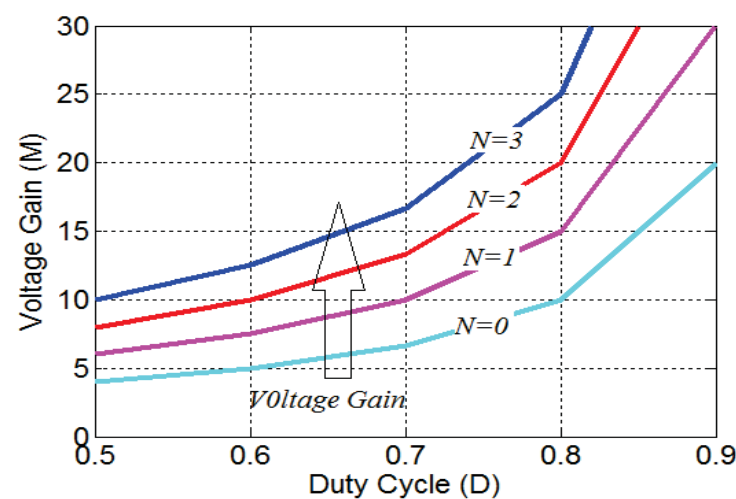

Fig. 5: Voltage gain as a function of $D$ and $N$ values

From (3)-(5), the ideal voltage gain is derived

$$
M_{\text {ideal }}=\frac{V_{0}}{V_{\text {in }}}=\frac{N+2}{(1-D)}
$$

The coupled inductor turns ratio $N$ can be adjusted to achieve the desired voltage conversion ratio without resorting to extreme duty cycle operation. The relationship between the static gain, duty cycle and turns ratio is plotted in Fig. 5. When the coupled inductor turns ratio is zero, the voltage gain of the proposed circuit is higher than that of the conventional boost converter. The voltage gain increases significantly at higher turns ratio.

\subsection{Power Devices Voltage Stress}

By neglecting the voltage ripple on the clamp capacitor, the voltage stress of the switch $S$ and clamp diode $D_{c}$ are the same and are equal to the voltage on the clamp capacitor given by

$$
V_{S}=V_{D c}=\frac{V_{\text {in }}}{(I-D)}=\frac{V_{o}}{(N+2)}
$$

The voltage stress of the output diode $D_{0}$ is the same with that of the regenerative diode, which is equal to the difference between the output voltage and the clamp capacitor voltage. However, it is always lower than the output voltage and is expressed as

$$
V_{D O}=V_{D r} \cong V_{O}-V_{C C}=\frac{(N+1) V_{i n}}{(1-D)}=\frac{(N+1) V_{o}}{(N+2)}
$$

\subsection{Current Stress}

The RMS current of the main switch is given by

$$
I_{R M S-S}=I_{\text {in }} \sqrt{D+\frac{2 N(1-D)}{(N+2)}+\frac{4 N^{2}(1-D)^{2}}{3 D(N+2)^{2}}}
$$

The RMS current regarding the clamp diode is

$$
I_{R_{\text {R }} D c}=I_{0}\left(\frac{2(N+D)}{(1-D) D}+\frac{N}{(1-D)}\right) \sqrt{\frac{(1-D)}{6}}
$$

The average current of the diodes is equal to the output current given by

$$
I_{D o}=I_{D o}=I_{o}
$$

\subsection{Diodes Reverse Recovery Alleviation}

The current falling rate of the output diode is controlled by the leakage inductance of the coupled inductor during Mode 3 given by

$$
d \frac{i_{D o}}{d t}=\frac{V_{o}}{N(N+2) L_{L k}}
$$

For the regenerative diode, its current falling rate is equally controlled by the leakage inductance at the end of Mode 4 derived as

$$
d \frac{i_{D r}}{d t}=\frac{(N+1) V_{O}}{N(N+2) L_{L k}}
$$

From (12) and (13) it can be concluded that the reverse recovery problem can be alleviated effectively by using the inherent leakage inductance of the coupled inductor to control their current falling rate. Furthermore as the turns ratio increases, a small leakage inductance is sufficient to alleviate the reverse recovery problem.

\section{Experimental Validation}

In order to verify the operation and evaluate the performance of the converter a $20 \mathrm{~V}$ input, $190 \mathrm{~V}$ output $250 \mathrm{~W}$ prototype circuit is built and tested in the laboratory. The specification of the converter along with the component ratings are derived from the analysis in section 3 . The specifications are listed in Table 1

\begin{tabular}{|l|l|}
\hline Output Power $\left(P_{o}\right)$ & $250 \mathrm{~W}$ \\
\hline Input Voltage $\left(V_{\text {in }}\right)$ & $20 \mathrm{~V}$ \\
Output Voltage $\left(V_{o}\right)$ & $190 \mathrm{~V}$ \\
Switching Frequency $\left(f_{s}\right)$ & $50 \mathrm{KHz}$ \\
Main Switches $(S)$ & FDP047AN \\
Diodes $\left(D_{c}, D_{o}\right.$ and $\left.D_{r}\right)$ & MBUR42050G \\
Clamp capacitor $\left(C_{c}\right)$ & $4.7 \mu \mathrm{F}$ \\
Switched Capacitor $\left(C_{m}\right)$ & $10 \mu \mathrm{F}$ \\
Output capacitor $\left(C_{o}\right)$ & $50 \mu \mathrm{F}$ \\
Turns Ratio $\left(n_{2} / n_{1}\right)$ & $1: 1.8$ \\
Magnetizing Inductance $\left(L_{m}\right)$ & $82 \mu \mathrm{H}$ \\
Leakage Inductance $\left(L_{L k}\right)$ & $1.3 \mu \mathrm{H}$ \\
\hline
\end{tabular}

\section{Table 1: Converter specifications}

The following experimental results are measured at $250 \mathrm{~W}$ full load conditions with $20 \mathrm{~V}$ input voltage. The drain source voltage of the power switch $v_{d s}$, the switch currents $I_{s}$, the voltage of the clamp diode $D_{c}$ and current are shown in Fig. 6 . It can be seen that maximum voltage across the devices is $60 \mathrm{~V}$, which is far less than the output voltage. This enables conduction loss reduction by allowing low rated devices with low $R_{d s-\text { on }}$ to be employed. Besides, the drain source voltage of the switch falls to zero prior to the application of turn-on gate signal, so ZCS is achieved for the power switch. The clamp turns-off naturally, which means there is no reverse recovery problem. A detail of the ZCS performance of the main switch is shown in Fig. 7. The output voltage and clamp circuit waveforms are shown in Fig. 8. Note that the voltage of the clamp capacitor is the same with that of the power switch and clamp diode. When the main switch turns-off the 


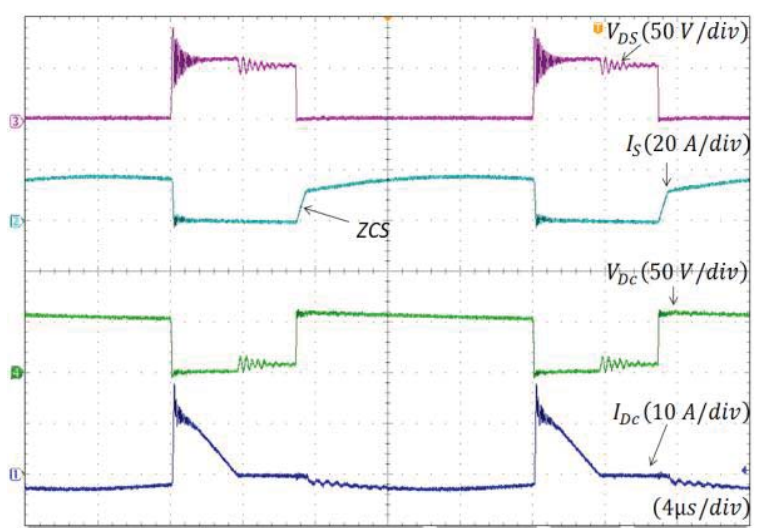

Fig. 6: Switch and clamp diode waveforms

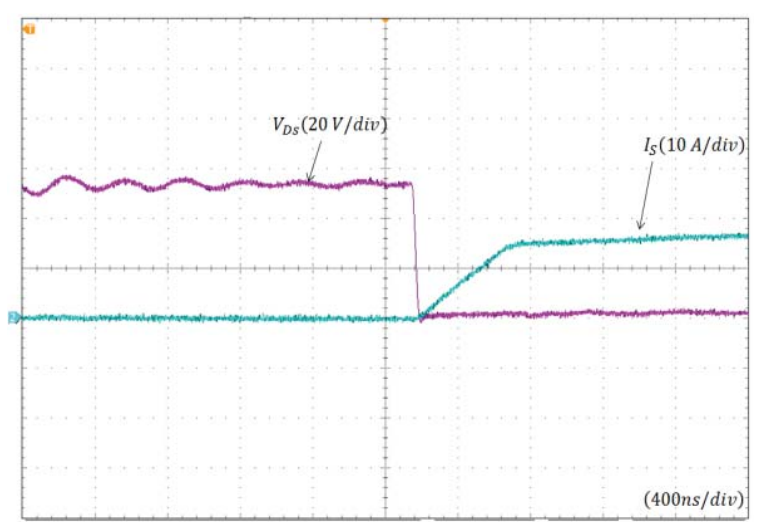

Fig. 7: ZCS details of the main switch

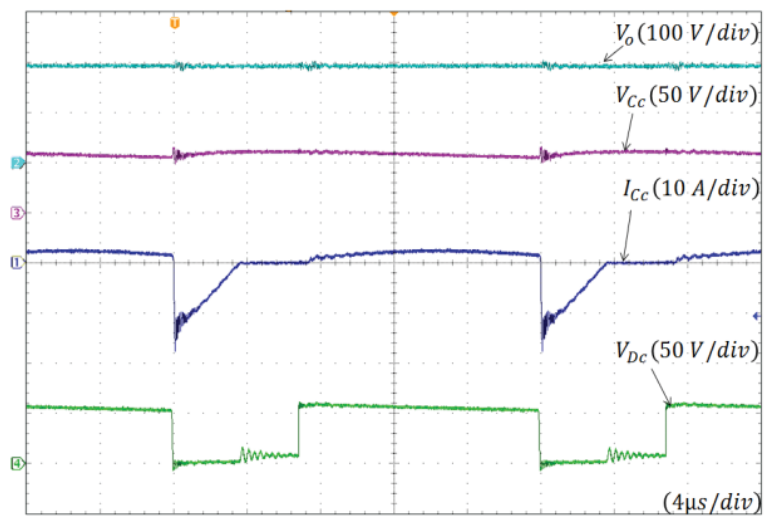

Fig. 8: Passive clamp circuit performance

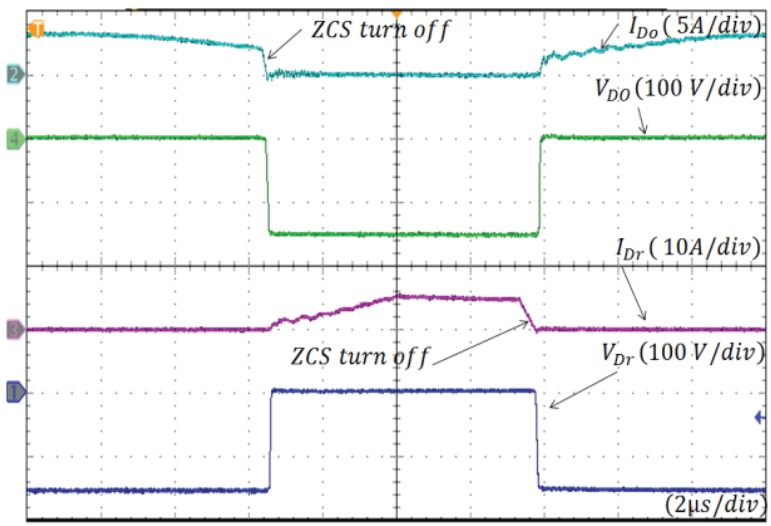

Fig. 9: Diodes ZCS turn off and reverse recovery alleviation

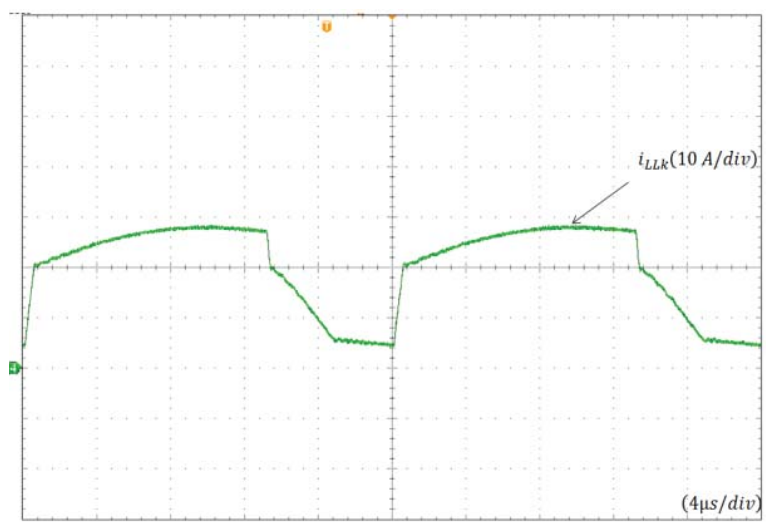

Fig. 10: leakage inductor current waveform

clamp diode conducts and the leakage inductor energy is transferred to the clamp capacitor. Also the passive clamp circuit uses part of the off time duration to reset the leakage energy. As illustrated in Fig. 9, the regenerative and output diodes turn off softly with ZCS, leading to the reverse recovery alleviation. The voltage across the diodes is $150 \mathrm{~V}$ which is also less than the converter output voltage of $190 \mathrm{~V}$. Fig. 10 illustrate the leakage inductor current, which is continuous over the entire switching cycle. However, the ripple magnitude is largely due to the magnetizing inductor and reflected secondary winding currents. Fig. 11 shows the measured efficiency of the converter. The efficiency is $93.5 \%$ for a wide load range and the maximum converter efficiency is $92.5 \%$ at full load

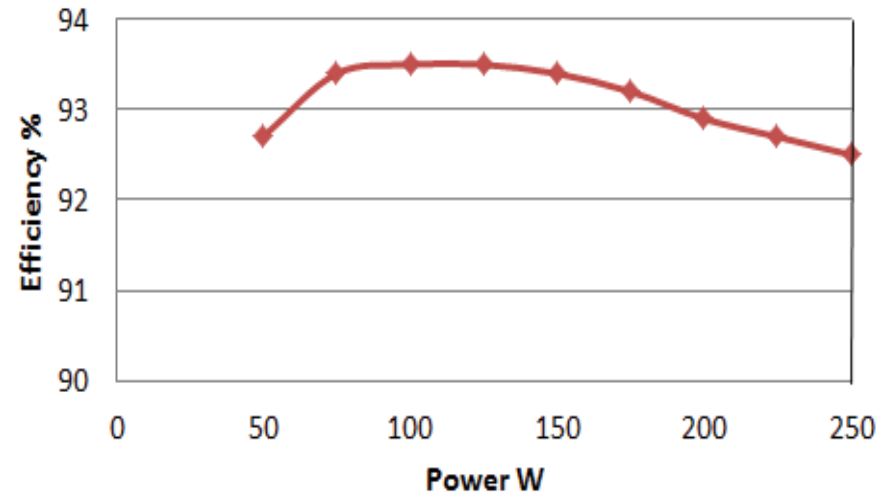

Fig. 11: Measure converter efficiency

\section{Conclusion}

In this paper a new single phase, high gain, boost converter with coupled inductor and switched capacitor is proposed. Thorough theoretical analysis of the circuit's principle of operation and experimental results presented from a $250 \mathrm{~W}$ prototype demonstrate the effectiveness of the proposed topology as a non-isolated, high gain, step-up power converter. The key advantages of the proposed converter are:

1. The voltage gain is easily enlarged by selecting the turns ratio of the coupled inductor. 
2. Semiconductor switch voltage stress is reduced; hence lower voltage rated devices can potentially be adopted to reduce conduction losses.

3. ZCS soft switching performance is readily achieved for the main switch, and ZCS is achieved for the diodes, further reducing losses in the circuit and minimizing reverse recovery loss

4. The leakage energy of the coupled inductor is recycled to the output.

\section{Acknowledgements}

The authors would like to acknowledge the Nigerian Petroleum Technology Development Fund (PTDF), and thank them for the invaluable PhD Scholarship Award for Musbahu Muhammad.

\section{References}

[1] Watson, R., F.C. Lee, and G.C. Hua, "Utilization of an active-clamp circuit to achieve soft switching in flyback converters", IEEE Trans. Power Electron., vol 11 no. 1, pp. 162-169 (1996).

[2] J. M. Kwon, E. H. Kim, B. H. Kwon, and K. H. Nam, "High-efficiency fuel cell power conditioning system with input current ripple reduction,"IEEE Trans. Ind. Electron, vol. 56, no. 3, pp. 826-834, (2009).

[3] Qun, Z. and F.C. Lee, High-efficiency, high step-up DCDC converters. IEEE Trans. Power Electron., vol. 18 no. 1, pp. 65-73 (2003).

[4] Yi Z, Li W, Yan D, He X, Lambert S, Pickert V. "High step-up boost converter with coupled inductor and switched capacitor", In: 5th IET International Conference on Power Electronics, Machines and Drives (PEMD). 2010, Brighton, UK: IEEE.

[5] Muhammad, M., M. Armstrong, and M. Elgendy, "Nonisolated DC-DC converter for high step-up ratio Applications", in Proc. Power Electronics and Applications (EPE'15 ECCE-Europe), 17th European Conference on. Geneva, Switzerland Sept. 2015.pp.1-10

[6] B. Axelrod, Y. Berkovich, and A. Ioinovici,"SwitchedCapacitor/Switched-Inductor Structures for getting Transformerless Hybrid DC-DC PWM Converters." IEEE Trans. Circuit and Sys, vol 55, no 2, pp. 687-696, (2008).
[7] M. Prudente, L.L Pfitscher, E. Gustavo, and R. gules, "Voltage Multiplier Cells Applied to Non-Isolated DCDC Converters." IEEE Trans. Power Electrons, vol. 23 no. 2, pp. 871-887,(2008).

[8] S. V. G. Oliveira and I. Barbi, "A three-phase step-up dcdc converter with a three-phase high-frequency transformer for dc renewable power source applications," IEEE Trans. Ind. Electron., vol. 58, no. 8, pp. 35673580, (2011).

[9] H.-L. Do, "A zero-voltage-switching dc-dc converter with high voltage gain," IEEE Trans. Power Electron., vol. 26, no. 5, pp. 1578-1586, (2011).

[10] Li W, Li W, He X, Lambert S, Pickert V. Performance analysis of ZVT interleaved high step-up converter with built-in transformer. In: 5th IET International Conference on Power Electronics, Machines and Drives (PEMD). 2010, Brighton, UK: IEEE.

[11] Muhammad, M., M. Armstrong, and M. Elgendy, "A Non-isolated Interleaved Boost Converter for High Voltage Gain Applications". IEEE Journal of Emerging and Selected Topics in Power Electronics, vol. 99 no 1, pp. 1-10, (2015).

[12] Zhao, Y., Li W, Yan D, X. He, "High step-up boost converter with passive lossless clamp circuit for nonisolated high step-up applications", IET Power Electrons, vol. 4 no. 8, pp. 851-859, (2010).

[13] Ahmeid, M., M. Armstrong, S. Gadoue "Parameter estimation of a DC-DC converter using a Kalman Filter approach". In: 7th IET International Conference on Power Electronics, Machines and Drives (PEMD) 2014.

[14] Chen, W., M. Armstrong, S. Gadoue. "System identification and adaptive control of a DC-DC converter using a current balancing ON/OFF control technique for optimal transient performance". In: 17th European Conference on Power Electronics and Applications (EPE'15 ECCE-Europe), 2015.

[15] Algreer, M., M. Armstrong, and D. Giaouris, Active Online System Identification of Switch Mode DC-DC Power Converter Based on Efficient Recursive DCD-IIR Adaptive Filter. IEEE Trans. on Power Electron, vol. 27. no 11, pp. 4425-4435, (2012).

[16] Algreer, M., M. Armstrong, and D. Giaouris, "Adaptive PD + I Control of a Switch-Mode DC-DC Power Converter Using a Recursive FIR Predictor". IEEE Trans. on Ind. Applications, vol 47, no 5, pp. 2135-2144, (2011). 